\title{
The Conceptual Synthesis and Development of a Multifunctional Lawnmower
}

\author{
Chun Quan Kang, Poh Kiat Ng * and Kia Wai Liew
}

Faculty of Engineering and Technology, Multimedia University, Jalan Ayer Keroh Lama, Bukit Beruang, Melaka 75450, Malaysia; kangchunquan@gmail.com (C.Q.K.); kwliew@mmu.edu.my (K.W.L.)

* Correspondence: pkng@mmu.edu.my

Citation: Kang, C.Q.; Ng, P.K.; Liew, K.W. The Conceptual Synthesis and Development of a Multifunctional Lawnmower. Inventions 2021, 6, 38 . https://doi.org/10.3390/

inventions6020038

Academic Editors: Francisco

Manzano Agugliaro and

Esther Salmerón-Manzano

Received: 21 April 2021

Accepted: 21 May 2021

Published: 28 May 2021

Publisher's Note: MDPI stays neutral with regard to jurisdictional claims in published maps and institutional affiliations.

Copyright: (c) 2021 by the authors. Licensee MDPI, Basel, Switzerland. This article is an open access article distributed under the terms and conditions of the Creative Commons Attribution (CC BY) license (https:// creativecommons.org/licenses/by/ $4.0 /)$.

\begin{abstract}
This study aims to develop a novel, original and multifunctional lawnmower through reviews of patent literature, research literature and variants of existing lawnmowers. After a detailed conceptualisation process, Autodesk Inventor (version 2019) is used for the finalised design drawing and stress simulation. The prototype is fabricated and tested through several experiments for usability validation which included tests on sound intensity level, cutting ability, polishing performance and battery power durability. Using Minitab 19, the data for the sound intensity and cutting ability experiments are analysed with two-sample $t$-tests. The data for the polishing performance and battery power durability experiments are analysed through observations, mean comparisons, and manual calculations. Significant differences are found to exist between the tested and control parameters in the context of each experiment, with the outcomes supporting the usability and performance of the present study's multifunctional lawnmower. This study showed that the prototype has the potential to solve not only some of the problems in conventional lawnmowers but also a few limitations in existing robotic lawnmowers. The outcome of this study intends to benefit society by advancing innovation in lawn maintenance and improving quality of life.
\end{abstract}

Keywords: conceptual synthesis; design; lawnmower; multifunctionality; usability

\section{Introduction}

A lawnmower is a machine that people use to cut grass. It uses specific rotating blades to cut grass to a certain height. Conventional lawnmowers, which can easily be found in hardware stores, include the gasoline or petrol-powered rotary push mower and a "ride on" mower. The similarity between these two types of lawnmowers include the fact that they both require manual operations and petrol as their main power source [1]. This similarity is also considered a weakness because operating these lawnmowers consumes a considerable amount of time and manpower, especially when it comes to mowing a large field such as a golf course or sports ground. According to a lawnmower manufacturer known as Encore, mowing time and productivity can be calculated with the assumption that the lawn is flat and with no landscaping obstacles. For example, approximately $60 \mathrm{~min}$ is required to cut only about $4047 \mathrm{~m}^{2}$ (1 acre) of turf for a $0.9 \mathrm{~m}$ (36 inch) walk behind a mower operating at $1.48 \mathrm{~m} / \mathrm{s}$ (3.3 mph) [2].

Furthermore, the power source used by conventional lawnmowers is neither renewable and nor environmentally friendly. Gasoline-powered lawn and garden equipment (GLGE) such as string trimmers, stump grinders and tractors often account for elevated degrees of localised emissions, including carbon dioxide $\left(\mathrm{CO}_{2}\right)$ and criteria pollutants. According to a research carried out in the US, all non-road sources including lawnmowers are responsible for about 242 million tonnes of pollutants every year, accounting for $17 \%$ of all VOC emissions, $12 \%$ of $\mathrm{NO}_{x}$ emissions, $29 \%$ of $\mathrm{CO}$ emissions, $4 \%$ of $\mathrm{CO}_{2}$ emissions, $2 \%$ of PM10 emissions, and 5\% of PM2.5 emissions [3].

There are also other minor concerns about conventional lawnmowers which affect the well-being of humans such as sound pollution and safety issues. Typical gas-powered 
mowers can create significant noise pollutions greater than 85 decibels [4]. The sound of a mower can be heard from a quarter mile away or more. Both the World Health Organisation (WHO) and Environmental Protection Agency (EPA) recommend that people limit their total exposure to noises to 5 min per day for very loud gas mowers, around 15 min a day for averagely loud mowers and $45 \mathrm{~min}$ a day for quieter mowers. Any prolonged period of exposure could cause hearing impairment or loss if hearing protection is not used [5].

In terms of safety, it was found that 934,394 lawnmower injuries were treated in US Emergency Departments from 2005 to 2015, with an average of 84,944 injuries annually [6]. Other reports found that around 212,258 children were treated in the US Emergency Departments for lawnmower-related injuries between 1990 and 2014 [7]. There is often more than one type of injury caused by conventional lawnmowers, which can include cuts, burns and fractures.

\section{Problem Statement}

One of the actions taken by some experts in solving the aforementioned problems is to design and produce robotic lawnmowers. A robotic lawnmower is an autonomous robot used to cut grass. Other similar products in the market are robot vacuums and robot mops. These types of working robots usually come with similar features such as the ability to work within a specified perimeter, obstacle avoidance and safety features. Consumers often substantially emphasise on basic service robots. Due to an increased demand for these robots, the related research in this area is growing.

According to a news report published by Allied Market Research, the worldwide autonomous lawnmower market size was reported as \$538 million in 2017 and is forecasted to touch $\$ 1437$ million by 2025 , registering a compound annual growth rate of $12.9 \%$ from 2018 to 2025 [8]. This steady advancement in market growth is one of the reasons why the robotic lawnmower market appears to grow rapidly in recent years.

Nonetheless, these solutions are still bounded by certain limitations such as high cost (the price is not proportional to the function) and high level of dependency on nonrenewable resources [9]. Another issue includes the lack of alternate features in robotic lawnmowers. Multifunctionality is important as less useful equipment eventually end up being eliminated over time, while the more universal and multifunctional ones remain in use [10].

However, there has yet to be a study that systematically conceptualises and develops a multifunctional lawnmower that is capable of addressing the above-mentioned limitations in robotic lawnmowers. Hence, this study aims to conceptually synthesise and develop a multifunctional lawnmower.

It is important to note that the scope of this study covers the resolution of limitations in smart lawnmowers which comprise high cost, heavy reliance on non-renewable resources and the inadequacy of multifunctional characteristics. This study does not cover other aspects of smart lawnmower designs such as the cutting blade, micro-controller, and movement algorithm for the robot. Therefore, aspects that are beyond the scope of this study will be adopted from existing smart lawnmowers through a benchmarking process.

\section{Literature Review}

\subsection{Locomotion Methods for Ground Robots}

Locomotion in robots includes a certain energy source (such as electric, nuclear, or geothermal power) conversion into mechanical power for vehicular movement. For a robotic machine to navigate through different geographical topographies, it is necessary for a platform to have multi-terrain manoeuvring capabilities [11]. Several locomotion methods that are suitable for ground mobile robots include the wheeled locomotion, track belt or slip locomotion, and legged robot. 


\subsubsection{Wheeled Locomotion}

Wheeled locomotion is commonly used by most moving devices such as automobiles and toys. This method allows for the achievement of high speeds while consuming less power and fewer active degrees of freedom. However, overcoming obstacles would normally be challenging with this method. To improve the stability of wheeled robots, the number of wheels is normally increased to four or more [12]. There are in total 3 different types of common wheels for autonomous robots [13]:

- Simple or standard wheels with two degrees of freedom, which are normally found around the centre shaft and point of contact.

- Castor wheels generally used in trolleys. These wheels can rotate around the axis and off-centre pivot point.

- Multidirectional wheels, which have three degrees of freedom with the help of rollers mounted on the outer periphery of the wheels.

\subsubsection{Track Belt or Slip Locomotion}

Using the track belt or slip locomotion eliminates some disadvantages from the wheeled locomotion. Wheeled robots can easily become stuck in a gap or hole that is bigger than the wheel size. The power efficiency for wheeled robots also drops while operating in loose terrain due to the increased rolling friction. The track belt locomotion which has a larger ground contact surface area is more efficient in loose terrain and has a lower risk of becoming stuck in holes and gaps [14].

The drawbacks of the track belt locomotion include slower movements and a higher energy consumption as compared to wheeled robots. However, these drawbacks can be minimised by lengthening the chains or changing their shape [15].

The steering system for tracked robots is different compared to wheeled robots. For tracked robots to change directions, the speed or direction of one tracked wheel needs to be different from the other. The SNR1 developed by the National Institute of Advanced Industrial Science and Technology (AIST) is one of such robots that uses a track belt locomotion. It has the capability to move on uneven terrains and staircases with the help of a single track along the wheels [11].

\subsubsection{Legged Locomotion}

Legged robots use articulated limbs such as leg mechanisms to provide locomotion. These robots move unlike the wheeled and track belt locomotion which intend to maintain continuous frictional contact with the ground. Many mechanisms for legged robots are imitated from humans and insects. For example, the Klann's mechanism is imitated from spiders [16].

These vehicles can move in irregular terrains by varying their leg configuration in order to adapt themselves to surface irregularities. The foot establishes contact with the ground in selected points according to terrain conditions. For these reasons, legs are inherently adequate systems for locomotion on irregular ground.

Legged robots tend to always require reprogramming since the pre-programmed ones would normally face challenges in interacting with the environment autonomously. Hence, a self-learning technique must be incorporated for these robots to adapt in different environments. In the late 1990s, researchers from MIT developed Genghis, a robot which has a reinforcement learning algorithm for walking [17]. Genghis was capable of learning the coordinates by the movement of its legs.

\subsection{Materials for Robots}

There are four groups of materials that tend to be commonly selected as the structural element for vehicle systems [18]. These four groups include wood, metal, composite materials, and plastics. Each group has their own characteristics, properties, potentials and disadvantages, and can be identified from the Ashby's material selection chart [19]. 
The indicator parameters of the selected material's mechanical properties include tensile strength, elastic modulus, and compressive strength.

\subsection{Microcontrollers}

A microcontroller is also known as a single board computer. It is a powerful microcomputer containing many on-board integrated circuits. Microcontrollers are created to perform a specified task and execute one specific application. This application can include automatic engine control systems, remote controls, power tools, toys and various types of office machines [20]. Some of the commonly used microcontrollers include the Arduino single-board microcontrollers [21] and Intel MCS-51 [22].

The Arduino is a more suitable choice for this study. It is a ready-to-use microcontroller board unlike the 8051, in which usage is time-consuming and error-prone, as it requires manual soldering for every pin. Furthermore, the Arduino allows an input voltage in the range of 6 to 20 volts, which means that a 12-volt battery could directly connect to the module without passing through any voltage regulator circuit as required by $8051 \mathrm{mi}-$ crocontrollers. However, there are also various types of Arduino boards available in the market such as the Arduino Uno, Arduino Mega, Arduino Micro and Arduino Nano. Thus, a comparison still needs to be done.

\subsection{Patent Literature Review}

\subsubsection{Automated Lawn Cutting and Vacuum System}

This invention not only includes the lawnmower but also lawn mowing accessories. The accessories refer to the mower home base and automated vacuum system. The lawn is equipped with multiple perimeter sensors placed around the perimeter and a mower home base which is placed at the corner of the lawn.

The mower home is used to store and recharge the lawnmower when it is not in use and remove the grass clippings. All tasks are performed automatically by the lawnmower, including the cutting and vacuuming of the grass, recharging, and storage and removal of grass clippings. The perimeter sensors are used to specify the working areas for the lawnmower [23].

\subsubsection{Automated Lawnmower or Floor Polisher}

The invention relates to an improved robotic lawnmower which uses obstacle- and grass touch-sensing for the motion control of a lawnmower through a computer interfaced feedback control. The invention uses infrared obstacle detection together with cut or uncut sensing to deliver feedback control to independent wheel drive motors when manoeuvring the lawnmower.

This invention aims to address the disadvantage of using a conventional automated lawnmower which requires a programmed lawn plot map or boundary track indicators such as perimeter sensors to work within a specified boundary. Alternatively, the automated lawnmower can also be used as a floor polisher by simply substituting the cutting blade with a polishing pad [24].

\subsubsection{Multifunctional Mobile Appliance}

This invention aims to perform multiple tasks which include mowing, vacuuming, mulching, polishing, weeding, painting, edging, fertilising, cultivating, raking, sanding, pressure washing or shampooing. The invention is also equipped with a work module distribution mechanism where all work modules are stored so that the mobile unit can switch them according to the respective tasks automatically. The invention is also embedded with a real-time kinematic global positioning system [25]. 


\subsection{Journal Review}

\subsubsection{The "Automated Mower Robo"}

A project entitled the "Automated Mower Robo" was proposed in order to solve the problems of using conventional lawnmowers powered by petrol. The project aimed to prototype an environmentally friendly electric solar grass cutter.

The design includes a solar-powered autonomous robot that communicates with the user through a smartphone's Bluetooth module. The design uses Arduino and ultrasonic sensors for obstacle detection. The prototype was tested on four different species of grass. The results in Table 1 show that the automated lawnmower is able to cut the grass to a minimum height of $80 \mathrm{~mm}$ [26].

Table 1. Calculated results on grass height for different types of grass before and after mowing [26].

\begin{tabular}{cccc}
\hline Types of Grass & \multicolumn{3}{c}{ Height (mm) } \\
\cline { 2 - 4 } & $\begin{array}{c}\text { Mean Grass } \\
\text { Height (Before } \\
\text { Mowing) }\end{array}$ & $\begin{array}{c}\text { Mean Grass } \\
\text { Height (After } \\
\text { Mowing) }\end{array}$ & $\begin{array}{c}\text { Expected Grass Height } \\
\text { (After Mowing) }\end{array}$ \\
\hline Elephant grass & 230.0 & 80.0 & 90.0 \\
Stubborn & 234.0 & 84.0 & 90.0 \\
Spare grass & 111.0 & 80.0 & 80.0 \\
Carpet grass & 70.5 & - & - \\
\hline
\end{tabular}

\subsubsection{Multi Sensor and Multifunctional Robot with Image Mosaic}

This invention was reported to possess the features of obstacle avoidance and linefollowing. The motion of the robot was based on clap sounds and light sensors. In this paper, the researchers reported that the line-following robot moves along the line using a certain feedback mechanism. Light sensors allow the robot to move according to the light and clap sensors allow the detection of clap sounds used to turn the robot on and off [27].

\section{Methodology}

The following steps are adhered to during the conceptualisation process:

- Step 1: Structural concept generation with combination chart

- Step 2: Screening and scoring of structural concepts

- Step 3: Key features scoring and combinations

- Step 4: Final concept generation

- Step 5: Material selection

- Step 6: Design drawing and stress simulation

\subsection{Structural Concept Generation with Combination Chart}

The basic components for a multifunctional lawnmower can be classified into two different groups, namely the mechanical and electronic components. The mechanical components include the mower shape, locomotion types and blade types. It is important to note that nylon string cutters (one of the substitutes for blades) are not included in the selection as these cutters often wear out faster than metal blades and are not suitable for smart lawnmowers that require minimal maintenance [28]. The electronic components comprise the microcontroller, battery and motor types for the blade and wheels. All the common choices for each component are listed in a combination chart as shown in Table 2. 
Table 2. List of all common choices for each component.

\begin{tabular}{|c|c|c|}
\hline \multirow{3}{*}{ Mechanical } & Driving mechanism & $\begin{array}{ll}\text { - } & \text { Continuous track } \\
\text { - } & 4 \text { equal size wheels } \\
\text { - } & 2 \text { big rear wheels and } 1 \text { round } \\
\text { ball wheel at the front }\end{array}$ \\
\hline & Shape & $\begin{array}{ll}\text { - } & \text { Circular } \\
\text { - } & \text { Rectangular }\end{array}$ \\
\hline & Blade type & $\begin{array}{l}\text { - } \\
\text { carge individual metal } \\
\text { - } \quad \text { Razor blades attached to a } \\
\text { spinning disc } \\
\text { - } \quad \text { Two swinging blades at the } \\
\text { front of the mower }\end{array}$ \\
\hline \multirow{4}{*}{ Electronic } & Battery type & $\begin{array}{ll}\text { - } & \text { Lead acid } \\
\text { - } & \text { Lithium-ion } \\
\text { - } & \text { Nickle-cadmium } \\
\end{array}$ \\
\hline & Motor type (blade) & $\begin{array}{ll}\text { - } & \text { Servo DC motor } \\
\text { - } & \text { Brushless DC motor } \\
\text { - } & \text { Stepper motor } \\
\text { - } & \text { Brushed DC motor } \\
\end{array}$ \\
\hline & Motor type (wheels) & - $\quad$ Gear motor \\
\hline & Arduino board types & $\begin{array}{ll}\text { - } & \text { Arduino Uno } \\
\text { - } & \text { Arduino Mega } \\
\text { - } & \text { Arduino Micro } \\
\text { - } & \text { Arduino Nano } \\
\end{array}$ \\
\hline
\end{tabular}

Different combinations of mechanical components lead to different basic structural concepts for the lawnmower. For this case, there are in total 5 different structural concepts. Table 3 shows the hand-sketched drawings of the bottom and isometric views for all the structural concepts.

Table 3. Bottom and isometric views of the structural concepts (hand sketches).

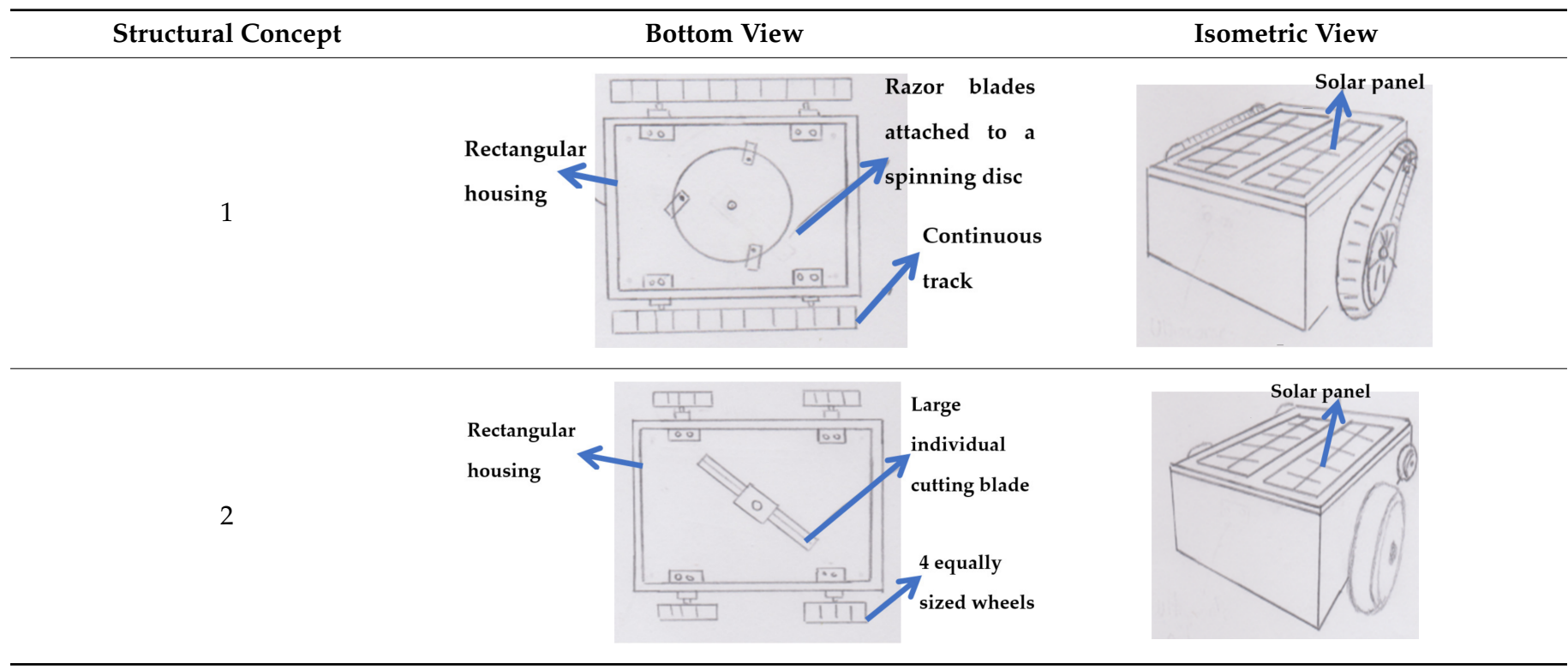


Table 3. Cont

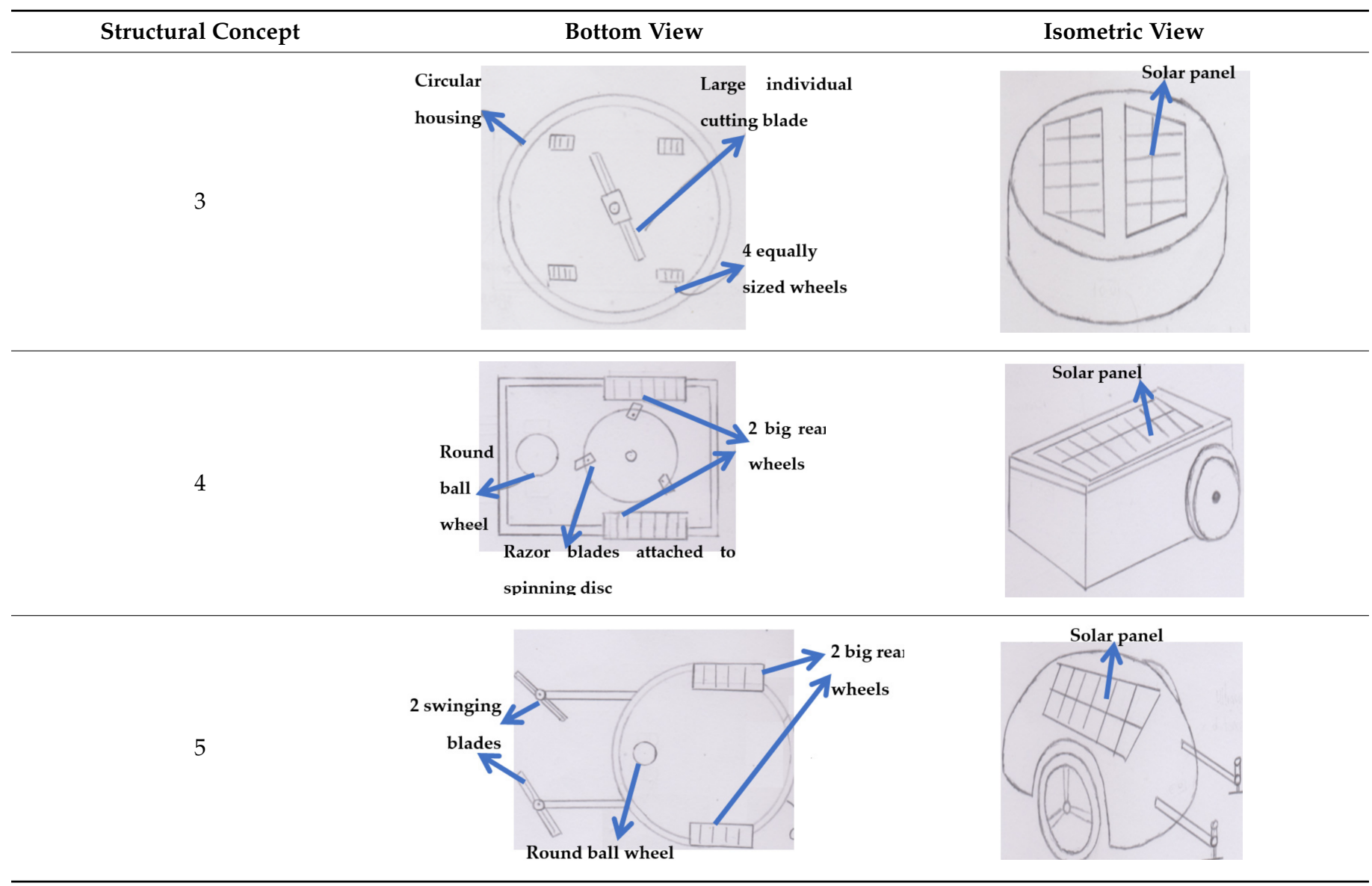

Structural concept 1 includes a rectangular-shaped robot with a continuous track driving mechanism and razor blades attached to a spinning disc. Structural concept 2 uses a rectangular-shaped robot with four equally sized wheels and a large individual cutting blade. Structural concept 3 combines a circular-shaped robot with four equally sized wheels and a large individual cutting blade. Structural concept 4 integrates a rectangular-shaped robot with two big rear wheels, one round ball wheel at the front, and razor blades attached to a spinning disc. Lastly, structural concept 5 combines a circular-shaped robot with two big rear wheels, one round ball wheel at the front, and two swinging blades at the front.

\subsection{Screening and Scoring of Structural Concepts}

During the screening process shown in Table 4 , it is found that only structural concepts 1,2 , and 4 are selected for the subsequent scoring process since the net scores of these concepts are found to be higher than the net score for structural concept 3 (the concept of reference).

It is important to note that the scoring and ranking processes are done by the main author of this study with some advice from his co-authors. The weightage and ratings are proposed by the main author based on his specific experience and knowledge of various lawnmower designs. The main author is also in the forefront of the design work and has a good grasp of the prototyping requirements, cost and ergonomics aspects involved in this study. Therefore, in reference to the main author's superior design sense in the specific area of lawnmower designs, the co-authors of this study concurred to the ratings and rankings provided by the main author. 
The rating system used for the scoring process ranged from 1 to 5 , and the description for each score is defined as such:

- $\quad$ 1: much worse than expected

- 2: worse than expected

- 3: matches expectations

- 4: exceeds expectations

- 5: greatly exceeds expectations

For the scoring process, each selection criterion is given a weight $(\mathrm{W})$. To determine the weighted score (WS) of each criterion, the rating (R) is multiplied by the weight $(\mathrm{WS}=\mathrm{R} \times \mathrm{W})$. The total weighted score for each structural concept is compared, and the structural concept with the highest score is prioritised for further development.

Table 4. Screening of basic structural concepts.

\begin{tabular}{cccccc}
\hline Selection Criteria & \multicolumn{5}{c}{ Basic Structural Concept } \\
\cline { 2 - 5 } & $\mathbf{1}$ & $\mathbf{2}$ & $\mathbf{3}^{*}$ & $\mathbf{4}$ & $\mathbf{5}$ \\
\hline Ease of manufacturing & 0 & + & 0 & + & - \\
Cutting width & 0 & 0 & 0 & 0 & + \\
Cost & - & + & 0 & + & - \\
Stability & + & + & 0 & + & - \\
Edging possibility & - & 0 & 0 & - & + \\
Ease of maintenance & + & 0 & 0 & 0 & 0 \\
Safety & + & 0 & 0 & + & - \\
\hline Sum of + & 3 & 3 & 0 & 4 & 2 \\
Sum of 0 & 2 & 4 & 7 & 2 & 1 \\
Sum of - & 2 & 0 & 0 & 1 & 4 \\
\hline Net score & 1 & 3 & 0 & 3 & -2 \\
Rank & 2 & 1 & 3 & 1 & 4 \\
Continue? & YES & YES & NO & YES & NO \\
\hline Note: ${ }^{*}$ Benchmarked concept. & & & &
\end{tabular}

Note: * Benchmarked concept.

The weight of each selection criterion depends on the constraints in the project. The major constraints include the project time and budgetary limitations. As it is important to ensure that the project is completed within these constraints, criteria such as ease of maintenance and ease of manufacturing are given high weights (30\% each). It is also highly desired that the multifunctional lawnmower performs optimally with regard to functionality which accounts for edging possibilities, stability and multifunctionality. Therefore, the weight for functionality is set at $40 \%$. During the scoring process, structural concept 4 obtained the highest score and is hence selected as the lawnmower's basic structure (refer to Table 5).

Since the electronic parts are not emphasised in the visualisation of the lawnmower's basic structure, their screening process is done individually. The screening processes for the battery, blade motor and Arduino board types are shown in Tables 6-8. In the end, the lead acid battery, brushed DC motor and Arduino Uno are selected. For the most part, the lead acid battery and brushed DC motor are selected over the other components due to lower cost, while the Arduino Uno is selected because it is easily accessible and less complex as contrasted to the other types of Arduino boards. 
Table 5. Scoring of basic structural concepts.

\begin{tabular}{|c|c|c|c|c|c|c|c|}
\hline \multirow{3}{*}{ Selection Criteria } & \multirow{3}{*}{ W (\%) } & \multicolumn{6}{|c|}{ Lawn Mower Base Structure } \\
\hline & & \multicolumn{2}{|c|}{ SC 1} & \multicolumn{2}{|r|}{ SC 2} & \multicolumn{2}{|r|}{ SC 4} \\
\hline & & $\mathbf{R}$ & WS (\%) & $\mathbf{R}$ & WS (\%) & $\mathbf{R}$ & WS (\%) \\
\hline Functionality & 40 & & & & & & \\
\hline Usage in different lawns & 10 & 4 & 40 & 3 & 30 & 4 & 40 \\
\hline Zero turning radius & 5 & 5 & 25 & 4 & 20 & 5 & 25 \\
\hline With high stability & 10 & 4 & 40 & 2 & 20 & 3 & 30 \\
\hline Wide cutting width & 5 & 4 & 20 & 4 & 20 & 3 & 15 \\
\hline Edging possibility & 10 & 2 & 20 & 3 & 30 & 3 & 30 \\
\hline Ease of maintenance & 30 & & & & & & \\
\hline Easily replaceable cutting blade & 15 & 4 & 60 & 3 & 45 & 4 & 60 \\
\hline Simple fastening methods & 15 & 3 & 45 & 3 & 45 & 3 & 45 \\
\hline Ease of manufacturing & 30 & & & & & & \\
\hline Low-cost material & 10 & 2 & 20 & 3 & 30 & 3 & 30 \\
\hline Low complexity of parts & 10 & 3 & 30 & 4 & 40 & 3 & 30 \\
\hline Low number of assembly steps & 10 & 2 & 20 & 3 & 30 & 4 & 40 \\
\hline Total score & & & 320 & & 310 & & 345 \\
\hline Rank & & & 2 & & 3 & & 1 \\
\hline Continue? & & & $\mathrm{NO}$ & & NO & & YES \\
\hline
\end{tabular}

Notes: W—Weight; SC—Structural concept; R—Rating; WS—Weighted score.

Table 6. Screening of battery types.

\begin{tabular}{cccc}
\hline Selection Criteria & \multicolumn{3}{c}{ Battery Types } \\
\cline { 2 - 4 } & Lead Acid & Nickle-Cadmium * & Lithium-Ion \\
\hline Lifecycle & - & 0 & - \\
Rechargeability & 0 & 0 & 0 \\
Safety & 0 & 0 & 0 \\
Cost & + & 0 & + \\
Power density & 0 & 0 & 0 \\
Self- discharge ability & + & 0 & + \\
Maintenance requirement (discharge) & + & 0 & + \\
Charging time & 0 & 0 & 3 \\
Sum of + & 3 & 0 & 2 \\
Sum of 0 & 4 & 8 & 1 \\
Sum of - & 1 & 0 & 2 \\
\hline Net score & 2 & 0 & NO \\
Rank & 1 & 3 & \\
Continue? & YES & NO & \\
\hline
\end{tabular}

Note: * Benchmarked battery.

The design process is extended to the detailed selection of each component. These components include the motors and battery. For the gear motor (drive motor), the maximum torque without slippage from the rear wheel is calculated to estimate the approximate torque required by the gear motor. This maximum torque without slippage is calculated using the basic equation, $T=F \times r$, where $F$ refers to tangential force (Newton) and $r$ refers to the radius of the wheel (metre).

Figure 1 shows the free-body diagram for the driving wheel. To perform the preceding calculation, the tangential force $(F)$, normal force $(N)$ and friction coefficient $(\mu)$ need to be known first. The $N$ is calculated as $23.125 N$ (obtained from static stress analysis at preliminary design stage), and the friction coefficient for the contact between the wheel and dry grass is between 0.5 to 0.8 . 
Table 7. Screening of blade motor types.

\begin{tabular}{ccccc}
\hline \multirow{2}{*}{ Selection Criteria } & \multicolumn{3}{c}{ Motor Type (Blade) } \\
\cline { 2 - 5 } & Stepper Motor * & Brushed DC Motor & Brushless DC Motor & Servo DC Motor \\
\hline Cost & 0 & 0 & - & - \\
Noise & 0 & + & + & + \\
Speed & 0 & 0 & 0 & + \\
Weight & 0 & 0 & + & 0 \\
Efficiency & 0 & 2 & 2 & 2 \\
Sum of + & 0 & 3 & 2 & 2 \\
Sum of 0 & 5 & 0 & 1 & 1 \\
Sum of & 0 & 2 & 1 & 1 \\
Net score & 0 & 1 & 2 & 2 \\
Rank & 3 & YES & NO & NO \\
Continue? & NO & & & \\
\hline
\end{tabular}

Note: * Benchmarked motor.

Table 8. Screening of Arduino board types.

\begin{tabular}{|c|c|c|c|c|}
\hline \multirow{2}{*}{ Selection Criteria } & \multicolumn{4}{|c|}{ Arduino Board Type } \\
\hline & Arduino Uno & Arduino Mega & Arduino Micro * & Arduino Nano \\
\hline Cost & 0 & - & 0 & 0 \\
\hline Availability & + & - & 0 & - \\
\hline Device complexity & + & - & 0 & 0 \\
\hline Sum of + & 2 & 0 & 0 & 0 \\
\hline Sum of 0 & 1 & 0 & 3 & 0 \\
\hline Sum of - & 0 & 3 & 0 & 1 \\
\hline Net score & 2 & -3 & 0 & -1 \\
\hline Rank & 1 & 4 & 2 & 3 \\
\hline Continue? & YES & $\mathrm{NO}$ & $\mathrm{NO}$ & $\mathrm{NO}$ \\
\hline
\end{tabular}

Note: * Benchmarked Arduino board.

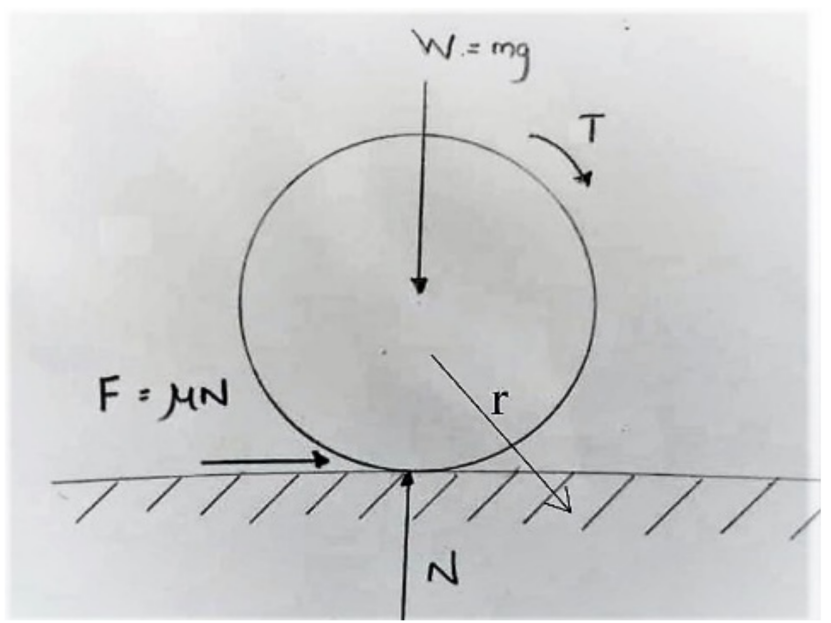

Figure 1. Free-body diagram for the driving wheel.

Therefore, the maximum torque without slippage can be calculated as $T=\mu N r=$ (0.8) $(23.125)(0.075)=1.388 \mathrm{Nm}$. Since the friction coefficient used in the equation is an estimated value, a gear motor with a torque that is close to the calculated maximum torque value $(1.388 \mathrm{Nm} \pm 10 \%)$ is acceptable. The selected gear motor is a $12 \mathrm{~V} 1 \mathrm{~A}, 24 \mathrm{rpm}$ and $1.47 \mathrm{Nm}$ DC motor. 
The other type of motor required by the blades is the high-speed brushed DC motor. The motor requires a minimum rotational speed of $3000 \mathrm{rpm}$ in order to create enough force and speed for the blades to cut grass. It is preferable for this motor to possess the same rated voltage $(12 \mathrm{~V})$ as the gear motor as this condition standardises the design and facilitates the selection of the other parts (battery and motor controller). The selected high-speed brushed DC motor is a $12 \mathrm{~V} 1.3 \mathrm{~A}, 10,000 \mathrm{rpm}$ and $0.032 \mathrm{Nm}$ DC motor.

Since the rated voltage for both motors is $12 \mathrm{~V}$, a $12 \mathrm{~V}$ battery is selected. However, the ampere-hour (Ah) for the battery still needs to be determined according to the requirements. The battery should be a lead-acid battery at an acceptable size (able to fit the smart lawnmower), with a minimum operating time of $2 \mathrm{~h}$ and good availability. The minimum Ah value of the battery can be calculated as the total current $\times$ minimum operating hours.

The total current for the three motors is calculated as $3.3 \mathrm{~A}(1 \mathrm{~A}+1 \mathrm{~A}+1.3 \mathrm{~A})$. Hence, the minimum ampere-hour for the battery is $6.6 \mathrm{Ah}$, whereby $\mathrm{Ah}=(3.3)(2)=6.6 \mathrm{Ah}$. Hence, a $12 \mathrm{~V}$ battery with 7.2 Ah is selected for this study.

\subsection{Key Features Scoring and Combinations}

Based on the benchmarking done on existing products, patents and journals, a total of 18 different features are extracted (refer to Table 9). This list also included some selfgenerated ideas. Since it is not possible to accommodate every single feature into one device, a scoring process is also done on the listed features.

Table 9. List of features from different sources.

\begin{tabular}{|c|c|c|}
\hline Sources & Product/Design & Key Features \\
\hline \multirow{4}{*}{ Product Review } & Robomow RX12 [29] & $\begin{array}{l}\text { 1. With unique edge mode (able to trim most of the } \\
\text { grass at the edge). } \\
\text { 2. Able to mow high grass. } \\
\text { 3. Adjustable blade height. }\end{array}$ \\
\hline & Husqvarna Automower 105 [30] & $\begin{array}{l}\text { 4. Works in any weather including raining days. } \\
\text { 5. Theft-proofed with a pin code and alarm. } \\
\text { 6. With lift sensors that stop blades when lawnmower } \\
\text { is lifted. }\end{array}$ \\
\hline & iRobot Terra [31] & $\begin{array}{l}\text { 7. Moves up and down in stripes (a square zig-zag } \\
\text { path). } \\
\text { 8. Able to cut close to the edge. }\end{array}$ \\
\hline & Agrirobot & $\begin{array}{l}\text { 9. With } 3 \text { types of charging modes; inductive, } \\
\text { contact-based and with ZCS active panel } \\
\text { (solar energy). } \\
\text { 10. Able to mow high grass. }\end{array}$ \\
\hline \multirow{3}{*}{ Patent } & $\begin{array}{l}\text { Automated lawn cutting and vacuum } \\
\text { system [23] }\end{array}$ & $\begin{array}{l}\text { 11. With automated vacuum system. } \\
\text { 12. Includes mower home base for recharging and } \\
\text { removal of grass clippings. }\end{array}$ \\
\hline & $\begin{array}{l}\text { Automated lawn mower or floor } \\
\text { polisher [24] }\end{array}$ & $\begin{array}{l}\text { 13. Able to work as a floor polisher after the mower } \\
\text { blade is substituted by a floor polishing pad. }\end{array}$ \\
\hline & Multifunctional mobile appliance [25] & $\begin{array}{l}\text { 14. Able to perform multiple tasks which include lawn } \\
\text { mowing, waxing, fertilising, polishing, edging } \\
\text { and vacuuming. }\end{array}$ \\
\hline \multirow[b]{2}{*}{ Journals } & Automated Mower Robo [26] & 15. Charges from sunlight while mowing the lawn. \\
\hline & $\begin{array}{l}\text { Multi sensor and multifunctional robot } \\
\text { with image mosaic [27] }\end{array}$ & $\begin{array}{l}\text { 16. With a sound sensor (clap sounds to turn the } \\
\text { mower on and off). }\end{array}$ \\
\hline Self-generated ideas & - & $\begin{array}{l}\text { 17. With water sprinkler system for watering grass. } \\
\text { 18. Able to work automatically or by remote control. }\end{array}$ \\
\hline
\end{tabular}


The scoring process for the listed features is shown in Table 10 with a rating system that is similar to previous scoring process. For this scoring process, probability weights are used for each selection criteria. After the scoring process, the features with a total score of less than 3 are omitted from the selection process. Table 11 shows the 11 features with scores that are equal or above 3 . Since some of the products or designs share the same feature, the total number of key features is reduced as shown in Table 10 (For example feature 1 and feature 8 ).

Table 10. Key features scoring table.

\begin{tabular}{|c|c|c|c|c|c|c|c|c|}
\hline \multirow{2}{*}{\multicolumn{2}{|c|}{ Key Features }} & \multicolumn{4}{|c|}{ Selection Criteria with Probability Weights (Total Weight $=1.0$ ) } & \multirow{4}{*}{$\begin{array}{c}\text { Score } \\
3.2\end{array}$} & \multirow{4}{*}{$\begin{array}{c}\text { Rank } \\
6\end{array}$} & \multirow{4}{*}{$\begin{array}{c}\text { Continue? } \\
\text { YES }\end{array}$} \\
\hline & & \multirow{3}{*}{$\begin{array}{c}\text { Cost (0.3) } \\
2 \\
0.6\end{array}$} & \multirow{3}{*}{$\begin{array}{c}\text { Simplicity (0.2) } \\
3 \\
0.6\end{array}$} & \multirow{3}{*}{$\begin{array}{c}\text { Feasibility (0.3) } \\
4 \\
1.2\end{array}$} & \multirow{3}{*}{$\begin{array}{c}\text { Suitability (0.2) } \\
4 \\
0.8\end{array}$} & & & \\
\hline 1,8 & $\mathrm{R}$ & & & & & & & \\
\hline 1,8 & WS & & & & & & & \\
\hline \multirow{2}{*}{2,10} & $\mathrm{R}$ & 2 & 4 & 4 & 4 & \multirow{2}{*}{3.4} & \multirow{2}{*}{4} & \multirow{2}{*}{ YES } \\
\hline & WS & 0.6 & 0.8 & 1.2 & 0.8 & & & \\
\hline \multirow{2}{*}{3} & $\mathrm{R}$ & 3 & 2 & 4 & 4 & \multirow{2}{*}{3.3} & \multirow{2}{*}{5} & \multirow{2}{*}{ YES } \\
\hline & WS & 0.9 & 0.4 & 1.2 & 0.8 & & & \\
\hline \multirow{2}{*}{4} & $\mathrm{R}$ & 3 & 4 & 5 & 4 & \multirow{2}{*}{4.0} & \multirow{2}{*}{1} & \multirow{2}{*}{ YES } \\
\hline & WS & 0.9 & 0.8 & 1.5 & 0.8 & & & \\
\hline \multirow{2}{*}{5} & $\mathrm{R}$ & 1 & 1 & 2 & 2 & \multirow{2}{*}{1.5} & \multirow{2}{*}{11} & \multirow{2}{*}{ NO } \\
\hline & WS & 0.3 & 0.2 & 0.6 & 0.4 & & & \\
\hline \multirow[b]{2}{*}{6} & $\mathrm{R}$ & 2 & 2 & 4 & 4 & \multirow[b]{2}{*}{3.0} & \multirow[b]{2}{*}{7} & \\
\hline & WS & 0.6 & 0.4 & 1.2 & 0.8 & & & YES \\
\hline & $\mathrm{R}$ & 4 & 2 & 2 & 4 & & & \\
\hline 7 & WS & 1.2 & 0.4 & 0.6 & 0.8 & 3.0 & 7 & YES \\
\hline & $\mathrm{R}$ & 1 & 1 & 2 & 3 & & & \\
\hline 9 & WS & 0.3 & 0.2 & 0.6 & 0.6 & 1.7 & 10 & $\mathrm{NO}$ \\
\hline & $\mathrm{R}$ & 3 & 3 & 4 & 4 & & & \\
\hline 11 & WS & 0.9 & 0.6 & 1.2 & 0.8 & 3.5 & 3 & YES \\
\hline & $\mathrm{R}$ & 1 & 3 & 3 & 3 & & & \\
\hline 12 & WS & 0.3 & 0.6 & 0.9 & 0.6 & 2.4 & 8 & NO \\
\hline & $\mathrm{R}$ & 4 & 5 & 4 & 2 & & & \\
\hline 13 & WS & 1.2 & 1.0 & 1.2 & 0.4 & 3.8 & 2 & YES \\
\hline & $\mathrm{R}$ & 1 & 1 & 1 & 2 & & & \\
\hline 14 & WS & 0.3 & 0.2 & 0.3 & 0.4 & 1.2 & 12 & $\mathrm{NO}$ \\
\hline & $\mathrm{R}$ & 2 & 3 & 4 & 4 & & & \\
\hline 15 & WS & 0.6 & 0.6 & 1.2 & 0.8 & 3.2 & 6 & YES \\
\hline & $\mathrm{R}$ & 2 & 2 & 2 & 1 & & & \\
\hline 16 & WS & 0.6 & 0.4 & 0.6 & 0.2 & 1.8 & 9 & $\mathrm{NO}$ \\
\hline & $\mathrm{R}$ & 3 & 3 & 3 & 3 & & & \\
\hline 17 & WS & 0.9 & 0.6 & 0.9 & 0.6 & 3.0 & 7 & YES \\
\hline & $\mathrm{R}$ & 4 & 2 & 4 & 3 & & & \\
\hline 18 & WS & 1.2 & 0.4 & 1.2 & 0.6 & 3.4 & 4 & YES \\
\hline
\end{tabular}


Table 11. List of selected key features with their respective total score.

\begin{tabular}{lc}
\hline \multicolumn{1}{c}{ Selected Lawnmower Features } & Total Score \\
\hline 1. Able to cut close to the edge. & 3.2 \\
2. Able to mow high grass. & 3.4 \\
3. Adjustable blade height. & 3.3 \\
4. Works in any weather including raining days. & 4.0 \\
5. With lift sensors that stop blades when lawnmower is lifted. & 3.0 \\
6. Moves up and down in stripes (a square zig-zag path). & 3.0 \\
7. With automated vacuum system. & 3.5 \\
8. Able to work as a floor polisher. & 3.8 \\
9. Charges from sunlight while mowing the lawn. & 3.2 \\
10. With water sprinkler system for watering grass. & 3.0 \\
11. Able to work automatically or by remote control. & 3.4 \\
\hline
\end{tabular}

These 11 selected features are further divided into five different groups with some constraints applied. First, each feature is allowed to only appear twice in different combinations. Secondly, the total score for each combination is to be within a range of 16 to 18 . The purpose of these constraints is to ensure that the five different combinations would be able to compete with one another in a fair situation.

To prolong the servicing time of the lawnmower and reduce the usage of nonrenewable energy when charging the lawnmower, feature 9 (Charges from sunlight while mowing the lawn) from Table 11 is selected as a pre-requisite feature and included in every combination. Table 12 shows the 5 different feature combinations along with their respective total scores. These combinations are prioritised for the final concept generation stage since their scores are within the prescribed range.

Table 12. List of combined features with their respective total scores.

\begin{tabular}{ccc}
\hline No. & Combination & Total Combination Score \\
\hline 1 & $1+2+3+7+9$ & 16.6 \\
2 & $2+4+5+6+9$ & 16.6 \\
3 & $1+8+9+10+11$ & 16.6 \\
4 & $4+6+7+9+10$ & 16.7 \\
5 & $3+5+8+9+11$ & 16.7 \\
\hline
\end{tabular}

\subsection{Final Concept Generation}

The five different combinations identified from the preceding section are integrated into the previously selected structural concept 4 to form the final concepts used to solve the problems deliberated in this study. The following are descriptions of the final concepts.

- Final concept 1: This concept includes an automated solar-charged lawnmower with a vacuum system. It can be used to cut tall grass to a desirable height. It has an "edge mode" feature that allows it to cut and vacuum close to the lawn's edge.

- Final concept 2: This concept includes an automated solar-charged lawnmower that also works on rainy days. It can be used to cut tall grass that is within a specified path. It has lift sensors to detect whenever the lawnmower is lifted up or turned over.

- Final concept 3: This concept includes a solar-charged two-mode (automated or remote control) lawnmower or floor polisher with a water sprinkler system. It has an "edge mode" feature that allows it to cut and vacuum close to the lawn's edge.

- Final concept 4: This concept includes an automated solar-charged lawnmower with a vacuum and water sprinkler system. The lawnmower is programmed such that it can move in a specified path and can operate even during rainy days.

- Final concept 5: This concept includes a solar-charged two-mode (automated or remote control) lawnmower or floor polisher with lift sensors. It is a lawnmower that can also work as a floor polisher by just substituting the cutting blade with a polishing pad and adjusting the height of the rotating pad wherever needed. 
The similar screening process is applied in order to obtain the best few final concepts. Table 13 shows the screening process for the final concepts, in which concepts 2,3 and 5 are selected. Finally, the best final concept is determined by a scoring process, in which concept 5 is chosen as shown in Table 14 .

Table 13. Screening of final concepts.

\begin{tabular}{cccccc}
\hline \multirow{2}{*}{ Selection Criteria } & \multicolumn{5}{c}{ Final Concept } \\
\cline { 2 - 6 } & $\mathbf{1}$ & $\mathbf{2}$ & $\mathbf{3}^{*}$ & $\mathbf{4}$ & $\mathbf{5}$ \\
\hline Ease of manufacturing & - & + & 0 & - & - \\
Ease of use & + & + & 0 & - & + \\
Cost & - & 0 & 0 & - & - \\
Stability & + & + & 0 & 0 & + \\
Feasibility & 0 & 0 & 0 & 0 & 0 \\
Multifunctionality & - & 0 & 0 & + & + \\
Ease of maintenance & 0 & 0 & 0 & - & - \\
Ease of manufacturing & - & + & 0 & - & - \\
\hline Sum of + & 2 & 3 & 0 & 1 & 3 \\
Sum of 0 & 2 & 4 & 7 & 2 & 3 \\
Sum of - & 3 & 0 & 0 & 4 & 0 \\
\hline Net score & -1 & 3 & 0 & -3 & 2 \\
\hline Rank & 3 & 1 & 2 & 4 & YES \\
\hline Continue? & NO & YES & YES & NO & \\
\hline Note: ${ }^{*}$ Benchmarked final concept. & & &
\end{tabular}

Table 14. Scoring of final concepts.

\begin{tabular}{|c|c|c|c|c|c|c|c|}
\hline \multirow{3}{*}{ Selection Criteria } & \multirow{3}{*}{ W (\%) } & \multicolumn{6}{|c|}{ Multifunctional Lawnmower } \\
\hline & & \multicolumn{2}{|c|}{ FC 2} & \multicolumn{2}{|c|}{ FC 3} & \multicolumn{2}{|c|}{ FC 5} \\
\hline & & $\mathbf{R}$ & WS (\%) & $\mathbf{R}$ & WS (\%) & $\mathbf{R}$ & WS (\%) \\
\hline Functionality & 50 & & & & & & \\
\hline Safe to use & 10 & 3 & 30 & 2 & 20 & 4 & 40 \\
\hline With high stability & 5 & 4 & 20 & 2 & 10 & 3 & 15 \\
\hline Multifunctionality & 10 & 2 & 20 & 4 & 40 & 4 & 40 \\
\hline Reduced human interaction & 15 & 5 & 75 & 4 & 60 & 4 & 60 \\
\hline Environmentally friendly & 10 & 4 & 40 & 4 & 40 & 4 & 40 \\
\hline Ease of use & 30 & & & & & & \\
\hline Minimal before-and-after cutting work & 10 & 3 & 30 & 4 & 40 & 3 & 30 \\
\hline Simple fastening methods & 5 & 4 & 20 & 3 & 15 & 4 & 20 \\
\hline Ease of maintenance & 15 & 3 & 45 & 3 & 45 & 3 & 45 \\
\hline Ease of manufacturing & 20 & & & & & & \\
\hline Low-cost material & 10 & 3 & 30 & 2 & 20 & 2 & 20 \\
\hline Low complexity of parts & 5 & 3 & 15 & 4 & 20 & 5 & 25 \\
\hline Low number of assembly steps & 5 & 3 & 15 & 3 & 15 & 3 & 15 \\
\hline Total Score & & & & & 25 & & 350 \\
\hline Rank & & & & & 3 & & 1 \\
\hline Continue? & & & & & $\mathrm{IO}$ & & YES \\
\hline
\end{tabular}

Notes: W-Weight; FC—Final concept; R-Rating; WS-Weighted score.

The final concept selected is the solar-charged two-mode lawnmower or floor polisher with lift sensors. Figure 2 shows the concept's hand-sketched drawing. 


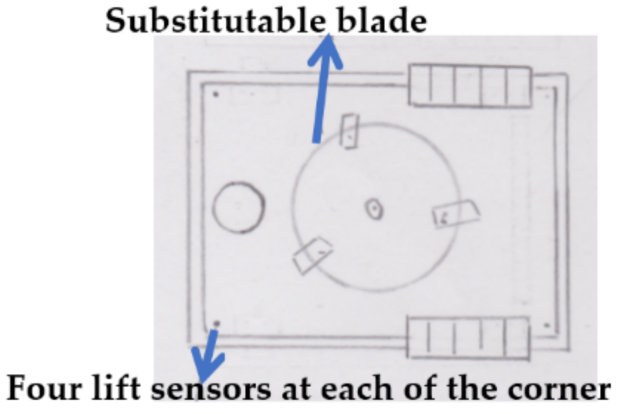

(a) bottom view

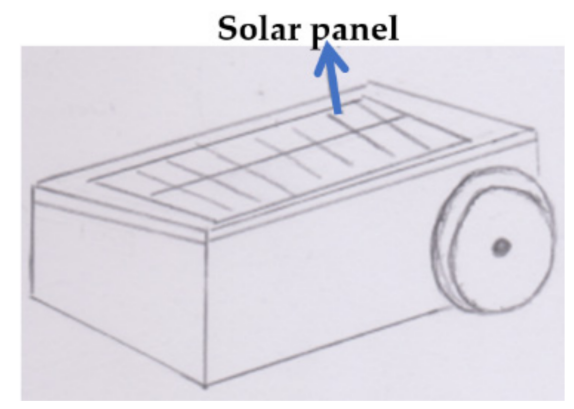

(b) isometric view

Figure 2. Hand-sketched drawing of final concept.

\subsection{Material Selection}

The material selection is performed for the multifunctional lawnmower's body (shell). The four groups of materials that are commonly used as structural elements for vehicle systems include wood, metal, composite materials, and plastics (from Section 2.2). The following material selection procedures are applied.

- Defining design requirements and deriving material indices

- Referencing the Ashby chart

- Screening and scoring

The design requirements are tabulated in Table 15, which comprises the main functions (the function of the lawnmower's body), objectives of using the "Bubble Chart" and constraints (fixed or must-have achievements by the design).

Table 15. Design requirements for lawnmower body.

\begin{tabular}{ll}
\hline Functions & The Shell and Chassis Support the Mower's Weight and Impact Load \\
\hline Objectives & $\begin{array}{l}\text { 1. Minimise the mass (to enhance efficiency) } \\
\text { 2. Minimise thickness (to reduce material cost) }\end{array}$ \\
\hline Constraints & $\begin{array}{l}\text { 1. Length is fixed } \\
\text { 2. Must not break or crack if physically struck by accident }\end{array}$ \\
\hline
\end{tabular}

To achieve the design requirement, the material must be able to withstand buckling and bending loads to a certain extent with minimal density. The material indices for buckling and bending are similar and represented as $M_{2}=E / \rho$, where $E$ refers to Young's modulus, and $\rho$ refers to density. However, there is another material index applied in the Ashby chart which is expressed as $M_{1}=E$. This material index is used to specify the minimum value of the material's Young's modulus. Since wood generally has a relatively low $E$ value compared to the other 3 groups of materials, $M_{1}$ is set at the wood region where $E$ is around $1 \mathrm{GPa}$. The establishment of $M_{1}$ helps eliminate about half of the materials in the Ashby chart.

The second material index, $M_{2}$ identifies materials with higher strength but lower density. With the establishment of material indices $M_{1}$ and $M_{2}$, only a quarter of the materials are left to be considered in the Ashby chart. Table 16 shows the remaining 4 materials selected from the Ashby chart after screening the materials using the material indices.

Based on the screening process in Table 17, wood is selected among the 4 materials. However, there are 3 types of commonly used wood which include hardwood, softwood, and manufactured board. Further screening revealed that the manufactured board is the most suitable wood type for this study (see Table 18). Lastly, different types of manufactured boards (medium density fibre board, plywood, hardboard, and chipboard) are scored using probability weights for each selection criteria. In the end, plywood is chosen to be the shell of the lawnmower (see Table 19). 
Table 16. Selected materials from Ashby chart.

\begin{tabular}{cccc}
\hline Material & $\left.\boldsymbol{M}_{\mathbf{1}} \mathbf{( G P a}\right)$ & $\boldsymbol{M}_{\mathbf{2}}\left(\mathbf{G P a} \cdot \mathbf{m}^{\mathbf{3}} / \mathbf{M g}\right)$ & Comments \\
\hline Wood I I grain & $8-20$ & $10-35$ & Good $M_{1}$; average $M_{2}$; cheap; common; reliable \\
\hline CFRP & $80-200$ & $45-120$ & Outstanding $M_{1}$; good $M_{2}$; very expensive; aesthetic \\
\hline GFRP & $18-30$ & $9-17$ & Good $M_{1}$; poor $M_{2}$; expensive \\
\hline Steel & $185-230$ & $29-22$ & Outstanding $M_{1}$; good $M_{2}$; heavy; common \\
\hline
\end{tabular}

Table 17. Screening of materials selected from "Bubble Chart".

\begin{tabular}{ccccc}
\hline Selection Criteria & \multicolumn{3}{c}{ Materials from the Ashby Chart } \\
\cline { 2 - 5 } & Wood & CFRP & GFRP & Steel \\
\hline Cost & + & - & 0 & + \\
Mass & - & + & 0 & - \\
Ease of machining & 0 & 0 & 0 & - \\
Ease of handling & + & 0 & 0 & - \\
Ease of fastening & + & 0 & 0 & - \\
Good heat insulator & 0 & - & 0 & 2 \\
Sum of + & 3 & 1 & 0 & 0 \\
Sum of 0 & 2 & 3 & 6 & 4 \\
Sum of - & 1 & 2 & 0 & -2 \\
Net score & 2 & -1 & 0 & 4 \\
Rank & 1 & 3 & 2 & NO \\
\hline Continue? & YES & NO & NO & \\
\hline
\end{tabular}

Note: * Benchmarked material.

Table 18. Screening of different wood type.

\begin{tabular}{cccc}
\hline \multirow{2}{*}{ Selection Criteria } & & Wood Type & \\
\cline { 2 - 4 } & Hardwood & Softwood ${ }^{*}$ & Manufactured Board \\
\hline Cost & - & 0 & 0 \\
Mass & - & 0 & + \\
Availability & - & 0 & + \\
Ease of machining & - & 0 & - \\
Moisture resistance & + & 0 & + \\
Hardness & + & 0 & 1 \\
Sum of + & 2 & 0 & 2 \\
Sum of 0 & 0 & 0 & 1 \\
Sum of - & 4 & 0 & 1 \\
Net score & -2 & 2 & YES \\
Rank & 3 & NO & \\
\hline Continue? & NO & & \\
\hline
\end{tabular}

Note: * Benchmarked wood.

Table 19. Scoring of different manufactured board type.

\begin{tabular}{|c|c|c|c|c|c|c|c|c|c|}
\hline \multirow{3}{*}{ Selection Criteria } & \multirow{3}{*}{$\begin{array}{c}\text { PW } \\
(\text { Total = 1.0) }\end{array}$} & \multicolumn{8}{|c|}{ Manufactured Board Type } \\
\hline & & \multicolumn{2}{|c|}{ MDFB } & \multicolumn{2}{|c|}{ Plywood } & \multicolumn{2}{|c|}{ Hardboard } & \multicolumn{2}{|c|}{ Chipboard } \\
\hline & & $\mathbf{R}$ & WS & $\mathbf{R}$ & WS & $\mathbf{R}$ & WS & $\mathbf{R}$ & WS \\
\hline High hardness & 0.3 & 3 & 0.9 & 5 & 1.5 & 4 & 1.2 & 1 & 0.3 \\
\hline Ease of machining & 0.2 & 4 & 0.8 & 3 & 0.6 & 3 & 0.6 & 2 & 0.4 \\
\hline Low material cost & 0.3 & 4 & 1.2 & 3 & 0.9 & 3 & 0.9 & 4 & 1.2 \\
\hline Low material mass & 0.2 & 3 & 0.6 & 3 & 0.6 & 4 & 0.8 & 4 & 0.8 \\
\hline Total score & & \multicolumn{2}{|c|}{3.5} & \multicolumn{2}{|c|}{3.6} & \multicolumn{2}{|c|}{3.5} & \multicolumn{2}{|c|}{2.7} \\
\hline Rank & & \multicolumn{2}{|c|}{2} & \multicolumn{2}{|c|}{1} & \multicolumn{2}{|c|}{2} & \multicolumn{2}{|c|}{3} \\
\hline Continue? & & \multicolumn{2}{|c|}{ NO } & \multicolumn{2}{|c|}{ YES } & \multicolumn{2}{|c|}{$\mathrm{NO}$} & \multicolumn{2}{|c|}{$\mathrm{NO}$} \\
\hline
\end{tabular}

Notes: PW—Probability weight; MDFB—Medium density fibre board; R—Rating; WS—Weighted score. 


\subsection{Design Drawing}

The dimension of the lawnmower in this study is first estimated by benchmarking three similar products known as the Robomow RX12, Husqvarna Automower 105 and iRobot Terra. Table 20 shows the estimated size (body dimension and rear wheel diameter) and mass for the robotic lawnmower. The estimated dimensions for length, width and height are $530 \mathrm{~mm}, 400 \mathrm{~mm}$, and $240 \mathrm{~mm}$, respectively. These values are referenced as input values for the design modelling using the Autodesk Inventor (version 2019).

Table 20. Estimation for the size and mass of the multifunctional lawnmower.

\begin{tabular}{cccccc}
\hline Product & Length $(\mathbf{m m})$ & Width $(\mathbf{m m})$ & Height $(\mathbf{m m})$ & Mass (kg) & $\begin{array}{c}\text { Rear Wheel } \\
\text { Diameter (mm) }\end{array}$ \\
\hline 1 & 508.00 & 419.10 & 254.00 & 7.26 & $\approx 200.00$ \\
2 & 550.00 & 390.00 & 250.00 & 6.70 & $\approx 200.00$ \\
3 & 530.00 & 405.00 & 202.00 & 8.50 & $\approx 200.00$ \\
\hline Mean & 529.33 & 404.70 & 235.33 & 7.49 & 200.00 \\
\hline Estimation & 530.00 & 400.00 & 240.00 & 8.00 & 200.00 \\
\hline
\end{tabular}

Notes: 1-Robomow RX12; 2-Husqvarna Automower 105; 3-iRobot Terra.

After all the components are finalised and confirmed, the assembly of the prototype commenced with parts such as the wheels (front and back), cover, blades, motors and sensors. Table 21 shows the isometric view and bottom view of the robotic lawnmower's shell and assembly drawings.

Table 21. Isometric and bottom view of the lawnmower (shell and assembly).

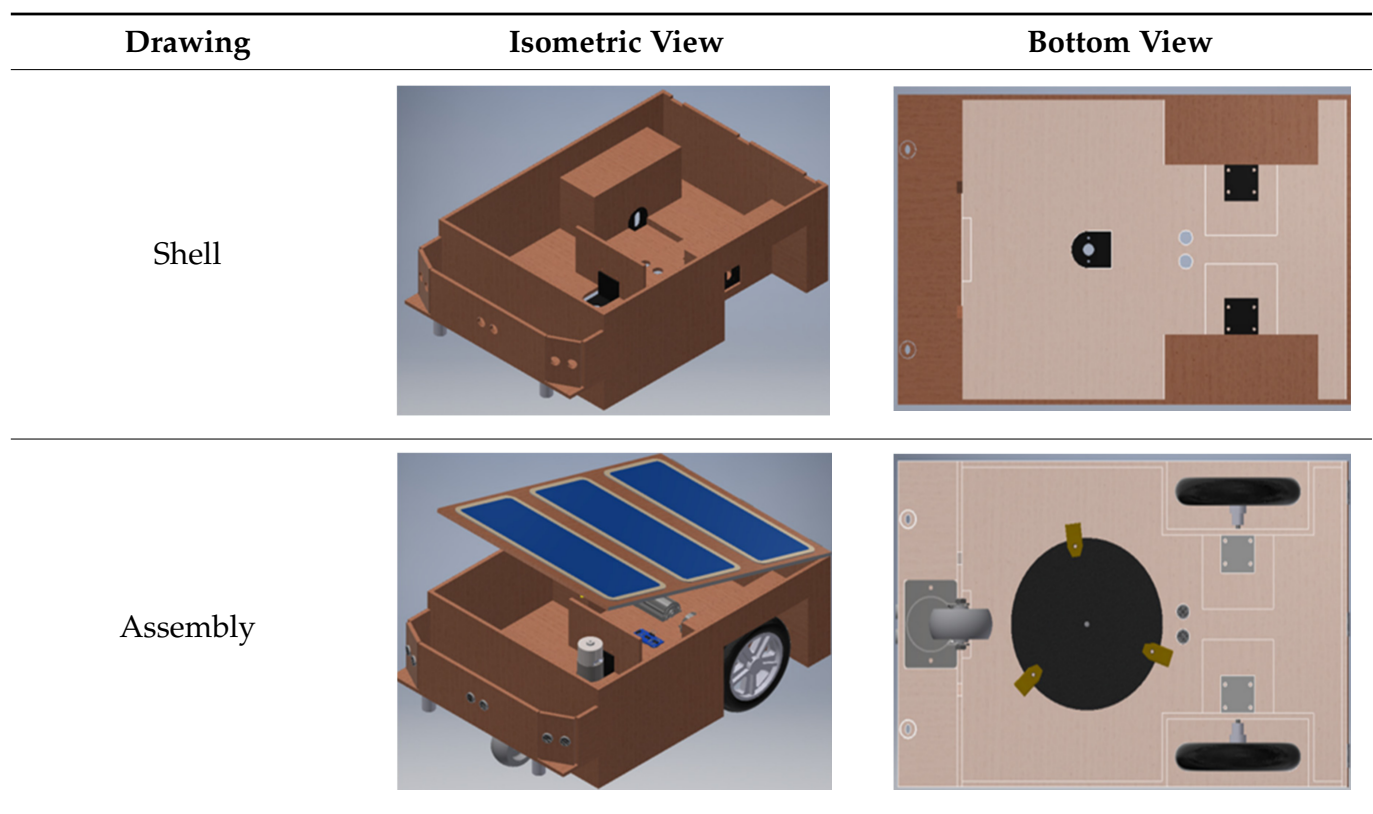

\subsection{Stress Analysis}

For the stress analysis, the reaction force on the body needs to be identified using static force analysis. Figures 3 and 4 show the free-body diagram of the lawnmower and the simplified free-body diagram with known and unknown variables respectively. The static force equilibrium equation when the lawnmower is in a static equilibrium state includes the summation of moment and summation of force acting on the system equated to zero:

$$
\begin{aligned}
& \Sigma M=0 \\
& \Sigma F=0
\end{aligned}
$$




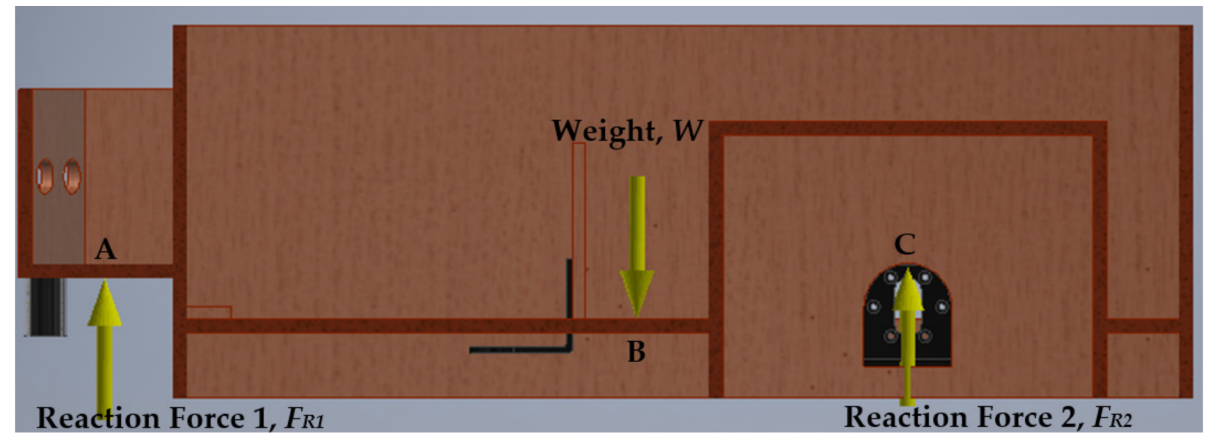

Figure 3. Free-body diagram of the lawnmower.

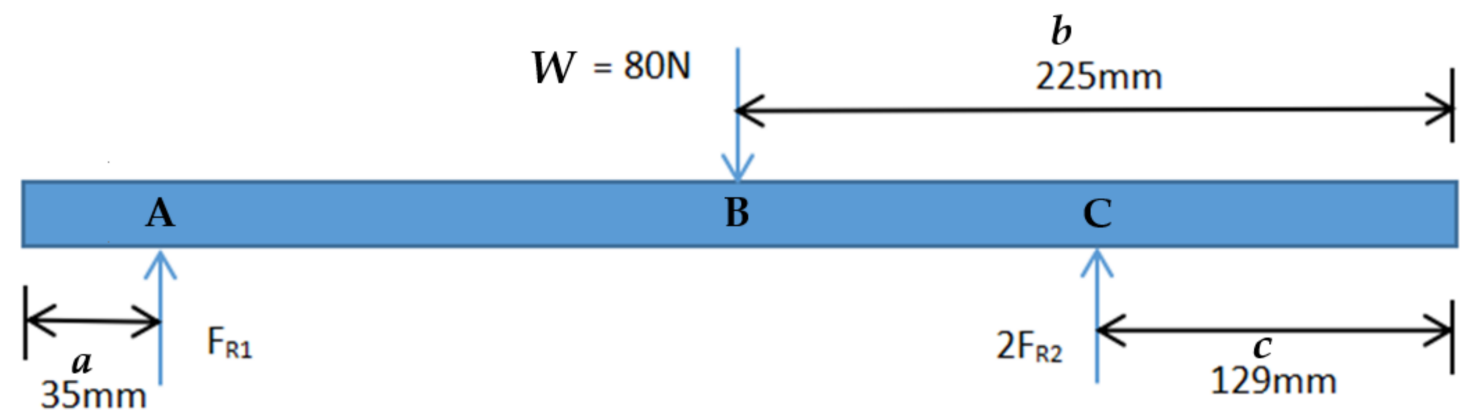

Figure 4. Simplified free-body diagram with known and unknown variables. Notes: $a$-distance from lawnmower front to point $\mathrm{A} ; b$-distance from point $\mathrm{B}$ to lawnmower rear; $c$-distance from point $\mathrm{C}$ to lawnmower rear; $F_{R 1}$-reaction force 1 ; $F_{R 2}$-reaction force $2 ; W$-lawnmower weight.

The total weight, $W$ of the lawnmower is estimated to be $80 \mathrm{~N}$ (since its mass is about $8 \mathrm{~kg}$ ) and the following assumptions are made.

Assumptions:

1. The total weight is acting at the centre of the lawnmower.

2. Roller reaction is at the front wheel.

3. Pin reaction is at the rear wheel.

Based on the static force equilibrium equation and assumptions, the pin reaction at the front $\left(F_{R 1}\right)$ is contributed by the front wheel, while the two pin reactions $\left(F_{R 2}\right)$ are contributed by the two rear wheels of the lawnmower.

Based on Equations (3) and (4), the reaction forces $F_{R 1}$ and $F_{R 2}$ are directly proportional to the weight, $W$ of the lawnmower. Other information obtained from both equations include the reaction force $F_{R 2}$ which is also directly proportional to the length denoted as $c$ and inversely proportional to length denoted as $b$. Furthermore, $F_{R 1}$ can be reduced by increasing the length denoted as $b$ and/or increasing the length denoted as $c$. Based on the finalised design of the lawnmower, the lengths denoted as $a, b$ and $c$ are represented as $35 \mathrm{~mm}, 225 \mathrm{~mm}$, and $129 \mathrm{~mm}$, respectively.

$$
\begin{gathered}
+C C W \sum M_{C}=0 \\
+C C W \sum M_{C}=W(b-c)-F_{R 1}(b)=0 \\
F_{R 1}=\frac{W(b-c)}{b} \\
+\uparrow \sum F_{y}=0 \\
+\uparrow \sum F_{y}=F_{R 1}+2 F_{R 2}-W=0 \\
F_{R 2}=\frac{W-F_{R 1}}{2}
\end{gathered}
$$




$$
\begin{gathered}
F_{R 2}=\frac{W-\frac{W(b-c)}{b}}{2} \\
F_{R 2}=\frac{W c}{2 b}
\end{gathered}
$$

After identifying all the reaction forces, these values are used for stress simulation with Autodesk Inventor (version 2019) in order to observe the stress distribution on the lawnmower in a static equilibrium state. Table 22 shows the simulation results for the von Mises stress, displacement, and safety factor. The maximum stress (0.4691 MPa) occurs at the rear wheel's mounting. On the other hand, the maximum displacement $(0.009708 \mathrm{~mm})$ after simulation occurs at the edge of the front surface. The minimum safety factor of the lawnmower in a static equilibrium state is 15 , which is a value that is higher than 1 . This outcome indicates that although a deflection of around $0.009708 \mathrm{~mm}$ exists at the base plate, the lawnmower is likely to still be structurally safe for use without any risks of static failure. Table 23 shows pictures of the prototype lawnmower.

Table 22. Stress simulation results for the prototype.

Von Mises Stress (MPa) Displacement (mm)

Table 23. Pictures of the prototype lawnmower.

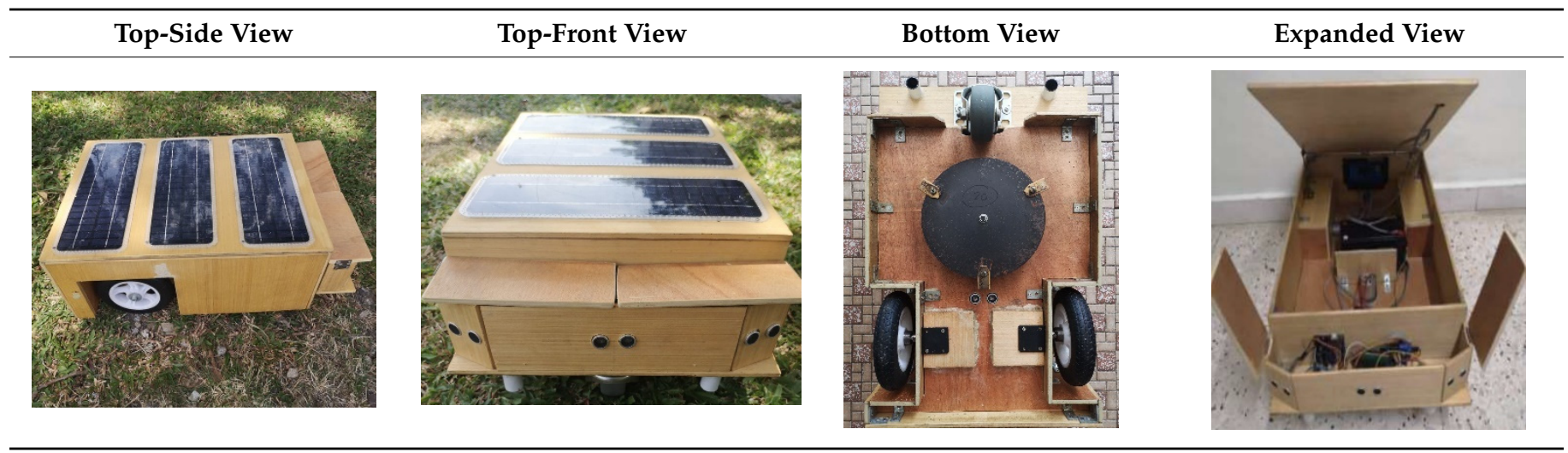

\section{Usability Tests}

A few usability tests were conducted with the prototype multifunctional lawnmower in order to test out its effectiveness in several functions. The following tests were carried out:

- $\quad$ Sound intensity level experiment

- Cutting ability experiment

- $\quad$ Polishing performance experiment 
- Battery power durability experiment

\subsection{Sound Intensity Level Experiment}

The objective of this experiment is to investigate whether there is a significant difference in sound intensity between a conventional lawnmower and a multifunctional lawnmower. For this experiment, the researchers were unable to compare the prototype with an existing smart lawnmower due to budgetary constraints. However, this study hypothesises that the prototype at least functions more quietly than a conventional lawnmower.

Thirty (30) sound intensity data samples (in $\mathrm{dB}$ ) are collected from the operating noise produced by the present study's multifunctional lawnmower and a conventional lawnmower. The sound level data are measured using a sound meter. The sound meter showed that the sound produced by the conventional lawnmower is akin to that of a busy street, while the sound produced by this study's lawnmower is akin to that of a quiet library.

Further statistical analysis is carried out using Minitab (version 19). The statistical test used is the two-sample $t$-test. The null and alternative hypotheses for this test are stated as such:

$\mathbf{H}_{0 \mathbf{a}}$. There is no significant difference in the sound intensity level between a conventional lawnmower and the multifunctional lawnmower.

$\mathbf{H}_{\mathbf{1 a}}$. There is a significant difference in the sound intensity level between a conventional lawnmower and the multifunctional lawnmower.

The results of the two-sample $t$-test in Table 24 show that $\mathrm{H}_{0 \mathrm{a}}$ is rejected and $\mathrm{H}_{1 \mathrm{a}}$ is supported as the $p$-value is less than $0.05[t(39)=127.62, p<0.05]$. The mean sound intensity level for the multifunctional lawnmower is $58.87 \mathrm{~dB}$ which is significantly lower (about $34 \%$ ) than the sound level produced by the conventional lawnmower (89.13 dB).

Table 24. Two-sample $t$-test for sound intensity level experiment.

\begin{tabular}{clc}
\hline Null hypothesis & $\mathrm{H}_{0 \mathrm{a}}: \mu_{1}-\mu_{2}=0$ \\
\hline Alternative hypothesis & $\mathrm{H}_{1 \mathrm{a}}: \mu_{1}-\mu_{2} \neq 0$ & \\
\hline$t$ & $d f$ & \\
\hline 127.62 & 39 & 0.000 \\
\hline
\end{tabular}

This experiment is very similar to another experiment that observed the relation of noise from lawn maintenance machines with health risks [4]. Researchers who studied the noise levels around $3 \mathrm{~m}$ away from the machines found the ride-on mower to be the safest, with the lowest average noise level of $75 \mathrm{~dB}$. In comparison, the multifunctional lawnmower in the present study emits a much lower sound intensity level, which validates its advantage in terms of sound comfort.

\subsection{Cutting Ability Experiment}

The objective of this experiment is to investigate whether there is a significant difference in grass height before and after the lawn is mowed by the multifunctional lawnmower. Thirty (30) square plots of grass (measuring $38 \times 38 \mathrm{~cm}$ ) are used in this experiment. Five (5) samples of grass height are measured and averaged for every plot.

A two-sample $t$-test is also used in this experiment. The null and alternative hypotheses for this test are stated below:

$\mathbf{H}_{\mathbf{0 b}}$. There is no significant difference in the grass height before and after the lawn is mowed by the multifunctional lawnmower.

$\mathbf{H}_{\mathbf{1} \mathbf{b}}$. There is a significant difference in the grass height before and after the lawn is mowed by the multifunctional lawnmower. 
Table 25 shows that $\mathrm{H}_{0 \mathrm{~b}}$ is rejected and $\mathrm{H}_{1 \mathrm{~b}}$ is supported as the $p$-value is less than $0.05[t(40)=11.11, p<0.05]$. The mean grass height after the lawn was mowed is $3.36 \mathrm{~cm}$ which is significantly shorter (about 51\%) than the grass height before the lawn was mowed $(6.84 \mathrm{~cm})$.

Table 25. Two-sample $t$-test for cutting ability experiment.

\begin{tabular}{|c|c|c|}
\hline Null hypothesis & \multicolumn{2}{|c|}{$\mathrm{H}_{0 \mathrm{~b}}: \mu_{1}-\mu_{2}=0$} \\
\hline Alternative hypothesis & \multicolumn{2}{|c|}{$\mathrm{H}_{1 \mathrm{~b}}: \mu_{1}-\mu_{2} \neq 0$} \\
\hline$t$ & $d f$ & $p$ \\
\hline 11.11 & 40 & 0.000 \\
\hline
\end{tabular}

In association with the above findings, another study of lawn mowing and grasscycling provided the authors with guidance on lawn maintenance particularly on how high to mow, when to mow and what to do with the grass clippings [32]. In a summary of proper mowing height for different types of grasses (see Table 26), it was found that the average proper mower height setting should be from 25.40 to $46.99 \mathrm{~mm}(2.54$ to $4.70 \mathrm{~cm})$. The mean cutting height for the present study's multifunctional lawnmower is around $3.36 \mathrm{~cm}$ which is within the suggested height setting range.

Table 26. Proper mowing height for different types of grasses [32].

\begin{tabular}{ccc}
\hline Grass Type & Mower Height Setting (mm) & $\begin{array}{c}\text { Mow When Grass at This } \\
\text { Height (mm) }\end{array}$ \\
\hline Bent grass & $12.70-25.40$ & $19.05-38.10$ \\
\hline Bermuda grass (common) & $25.40-38.10$ & $38.10-57.15$ \\
\hline Bermuda grass (hybrid) & $12.70-25.40$ & $19.05-38.10$ \\
\hline Buffalo grass & $25.40-50.80$ & $38.10-76.20$ \\
\hline Kentucky bluegrass & $38.10-63.50$ & $57.15-95.25$ \\
\hline Kikuyu grass & $25.40-38.10$ & $38.10-57.15$ \\
\hline Perennial grass & $38.10-63.50$ & $57.15-95.25$ \\
\hline Tall fescue & $38.10-76.20$ & $57.15-114.3$ \\
\hline St. Augustine grass & $25.40-50.80$ & $38.10-76.20$ \\
\hline Zoysia grass & $12.70-38.10$ & $19.05-57.15$ \\
\hline Average (mm) & $25.40-46.99$ & $38.10-70.49$ \\
\hline
\end{tabular}

It is important to note that this test verifies the ability of the prototype to perform its intended function, which is to shorten the grass height. The test does not necessarily prove that the prototype cuts grass better than conventional lawnmowers or existing smart lawnmowers. However, the literature support on grass height comparisons helps identify that the grass is shortened to an appropriate or acceptable height.

\subsection{Polishing Performance Experiment}

The objective of this experiment is to observe the performance of the multifunctional lawnmower's alternate function, which includes floor polishing. The experiment used mosaic tiles as the observed samples, and an illumination meter as the measurement instrument.

Using the illumination meter, a parameter known as illuminance (in lux) is measured. Table 27 shows the illuminance data for 3 different samples before and after the floor is polished. The illuminance of the floor increased by $20.7 \%$ after the polishing. Hence, the experiment concludes that there is a difference in illuminance before and after the floor is polished by the multifunctional lawnmower. 
Table 27. Illuminance before and after the floor is polished.

\begin{tabular}{ccc}
\hline \multirow{2}{*}{ Tile Sample } & \multicolumn{2}{c}{ Illuminance (Lux) } \\
\cline { 2 - 3 } & Before & After \\
\hline 1 & 28.0 & 38.0 \\
2 & 25.0 & 33.0 \\
3 & 31.0 & 35.0 \\
Mean & 28.0 & 35.3 \\
\hline
\end{tabular}

The present study's polishing experiment is similar to another research which investigated the effectiveness of banana peel as a substitute for commercial floor wax [33]. Instead of purely depending on observations, this prior research used a wide light range meter to measure the illuminance of different waxed floors for the comparison of shininess.

The results for shininess using the wide light range meter are shown in Table 28. Although not directly comparable in terms of results, this methodology is consistent with the one used in the present study since both performed a comparison on the shininess of floors through the measurement of illuminance.

Table 28. Shininess using wide light range meter [33].

\begin{tabular}{|c|c|c|c|}
\hline \multirow{2}{*}{ Tria } & & \multicolumn{2}{|c|}{ Shininess (lux) } \\
\hline & & Using Banana Peel Floor Wax & Using Brand X Floor Wax \\
\hline \multirow{3}{*}{ Ceramic Tile } & 1 & 16.6 & 16.3 \\
\hline & 2 & 16.1 & 15.1 \\
\hline & 3 & 16.1 & 15.2 \\
\hline \multirow{3}{*}{ Wood Parquet } & 1 & 12.4 & 11.1 \\
\hline & 2 & 13.2 & 11.6 \\
\hline & 3 & 12.1 & 11.3 \\
\hline \multirow{3}{*}{ Scarlet Oak } & 1 & 6.8 & 6.3 \\
\hline & 2 & 7.4 & 6.6 \\
\hline & 3 & 7.5 & 6.6 \\
\hline \multicolumn{2}{|c|}{ Mean } & 12.02 & 11.12 \\
\hline
\end{tabular}

\subsection{Battery Power Durability Experiment}

A set of calculations are done to estimate the battery power durability of the multifunctional lawnmower. The operation time for two different scenarios (one with the solar charge controller and another without the solar charge controller) is calculated and shown in Table 29. Similar equations for charging and operation time have been used in another design project known as the Automated Mower Robo [26].

Table 29. Calculation of lawnmower operation time.

\begin{tabular}{cc}
\hline & Operation Time (hours) \\
\hline Without Solar Charge Controller & $\begin{array}{c}\text { Operation time }(\mathrm{h})=\text { Battery capacity }(\text { Ah }) / \text { Total current }(\mathrm{A}) \\
\text { Operation time }(\mathrm{h})=7.2 / 3.3=2.18 \mathrm{~h}\end{array}$ \\
$\begin{array}{c}\text { With Solar Charge Controller } \\
\text { panel total current }\end{array}$ \\
$\begin{array}{c}\text { Extra battery capacity }(\text { Ah })=\text { Effective charging time }(\mathrm{h}) \times \text { Solar } \\
\text { panption: effective charging time per day is } 3 \mathrm{~h}\end{array}$ & $\begin{array}{c}\text { Extra battery capacity }(\mathrm{Ah})=3 \times(13.5 / 12)=3.38 \mathrm{Ah} \\
\text { Operation time }(\mathrm{h})=(7.2+3.38) / 3.3=3.21 \mathrm{~h}\end{array}$ \\
\hline
\end{tabular}

Note: Ah stands for ampere-hours.

The total current was calculated as 3.3 A. With the battery capacity known, the operation time for the multifunctional lawnmower is calculated as $2.18 \mathrm{~h}$ (130.8 min). The peak sun hours in Malaysia occur from 12 to 3 p.m. ( 3 h) Thus, the solar panel would work 
best during this period. The solar panel used for the design is rated with $12 \mathrm{~V}, 4.5 \mathrm{~W}$. Hence, the solar panel's total current is calculated by the total power in watts divided by the rated voltage in volts. Using the peak sun hours as the effective charging time, the extra battery capacity can then be calculated, followed by the calculation of the operation time. The operation time for the lawnmower with the solar charge controller is $3.21 \mathrm{~h}(192.6 \mathrm{~min})$.

However, the recorded times for the operation with and without the solar charge controller are measured to be $118.5 \mathrm{~min}$ and $187.3 \mathrm{~min}$ respectively. The measured times are lesser than the calculated times by around 2 to $10 \%$. The time difference between calculated and measured time may be due to the power consumption of other minor electronic parts such as the small bulbs on the microcontroller, motor controller modules, Bluetooth module and infrared sensors which are not considered in the calculation of operation time. The measured operation time with the solar charge controller is $36.73 \%$ longer than the operation time without the solar charge controller.

\section{Conclusions}

The aim of this study was to develop a novel, original, and multifunctional lawnmower through reviews of patent literature, research literature and variants of existing lawnmowers. The usability of the lawnmower was also successfully validated through data-driven experimentations.

The results from the sound intensity experiment showed that the average sound intensity level of the multifunctional robotic lawnmower is $58.87 \mathrm{~dB}$, which is akin to that of a sound level in a library. This finding shows that the present study's lawnmower has the potential to reduce noise pollution and noise-induced health risks. In terms of multifunctionality, the prototype lawnmower also rendered the alternate function of a floor polisher and successfully improved the floor's shininess by about $20 \%$.

The results of the battery power durability experiment showed that the operation time increased by around $37 \%$ when the solar panels were connected. The usage of solar panels not only improved the efficiency of the lawnmower, but also reduced non-renewable energy usage. This achievement is meritorious since Malaysia is still highly dependent on non-renewable resources for power supply with regard to the lawnmower industry.

Finally, the cost of producing a single prototype lawnmower is around 630 MYR. By considering the variable cost, fixed cost, break-even analysis and profit margin, the prototype can be priced at approximately 1000 MYR, which is about 10 times cheaper than other competitors in the market. On the whole, the multifunctional lawnmower proposed in this study is proven to be more effective than other conventional robotic lawnmowers with regard to its cost, multifunctionality and low reliance on non-renewable resources. A patent has been filled for this invention on 11 November 2020 with the patent application number PI2020005912. The invention's name is also known as the Multifunctional Robot.

For future research, more tests can be done on the lawnmower's locomotion ability on different terrains and cutting ability for different types of grass. In addition, advanced problem-solving tools such as TRIZ or Design Thinking can be used to further develop the multifunctional lawnmower in terms of its degree of inventiveness. Lastly, further analysis pertaining to the invention's polishing attribute (i.e., the polisher's design requirements, design conceptualisation and selection, stress analysis and material selection) can be done for future research.

Although more studies are required to fully develop a commercial-ready multifunctional lawnmower, this study not only opens an avenue for researchers to conduct more investigations on smart lawn mowing machines, but also assists Malaysia in her journey towards embracing the fourth industrial revolution.

Author Contributions: Conceptualization, C.Q.K. and P.K.N.; Data curation, C.Q.K.; Formal analysis, C.Q.K. and K.W.L.; Investigation, C.Q.K. and P.K.N.; Methodology, C.Q.K., P.K.N. and K.W.L.; Project administration, P.K.N.; Resources, P.K.N.; Supervision, P.K.N. and K.W.L.; Validation, C.Q.K.; Writing—original draft, C.Q.K. and P.K.N.; Writing—review \& editing, C.Q.K., P.K.N. and K.W.L. All authors have read and agreed to the published version of the manuscript. 
Funding: This research received no external funding.

Institutional Review Board Statement: Not applicable.

Informed Consent Statement: Not applicable.

Data Availability Statement: This project contains the following underlying data: Data Availability Sheet.docx (stress analysis for preliminary design, experimental data, program codes and circuit diagram). The data can be found at Figshare: doi.org/10.6084/m9.figshare.14617122 (accessed on 21 May 2021). Data are available under the terms of the Creative Commons Attribution 4.0 International license (CC-BY 4.0).

Acknowledgments: The researchers gratefully thank the Faculty of Engineering and Technology as well as Multimedia University for their support in allowing this research to be carried out. The researchers also thank Chi Keng Kang for his useful comments on matters related to this research project.

Conflicts of Interest: The authors report no conflict of interest.

\section{References}

1. Khodke, K.R.; Kukreja, H.; Kotekar, S. Literature Review of Grass Cutter Machine. Int. J. Emerg. Technol. Eng. Res. 2018, 6, 97-101.

2. Calculating Mowing Times and Productivity. Encore Power Equipment. 2012. Available online: http:/ /www.encoreequipment. com/wordpress/wp-content/uploads/2012/06/Mowing-Times-and-Productivity.pdf (accessed on 17 November 2019).

3. Banks, J.L. National Emissions from Lawn and Garden Equipment. 2015. Available online: http://www.arb.ca.gov/msei/ offroad/pubs/offroad_overview.pdf (accessed on 17 November 2019).

4. Tint, P.; Tarmas, G.; Koppel, T.; Renihold, K.; Kalle, S. Vibration and Voice Caused by Lawn Maintenance Machines in Association with Risk to Health. Agron. Res. Biosyst. Eng. 2012, 10, 251-260.

5. Niquette, P.A. Noise exposure: Explanation of OSHA and NIOSH safe exposure limits and the importance of noise dosimetry. Can. Hear. Rep. 2012, 9, 22-29.

6. Harris, C.; Madonick, J.; Hartka, T.R. Lawn mower injuries presenting to the emergency department: 2005 to 2015. Am. J. Emerg. Med. 2018, 36, 1565-1569. [CrossRef] [PubMed]

7. Ren, K.S.; Chounthirath, T.; Yang, J.; Friedenberg, L.; Smith, G.A. Children treated for lawn mower-related injuries in US emergency departments, 1990-2014. Am. J. Emerg. Med. 2017, 35, 893-898. [CrossRef] [PubMed]

8. Kadam, S.; Bhandalkar, A. Robotic Lawn Mower Market by Range, End User, and Distribution Channel: Global Opportunity Analysis and Industry Forecast, 2018-2025. 2018. Available online: https://www.alliedmarketresearch.com/press-release/ robotic-lawn-mower-market.html (accessed on 19 November 2019).

9. Samsudin, M.S.N.; Rahman, M.M.; Wahid, M.A. Power Generation Sources in Malaysia: Status and Prospects for Sustainable Development. J. Adv. Rev. Sci. Res. 2016, 25, 11-28.

10. Lim, S.; Ng, P. Synthesisation of Design Features for Multifunctional Stretcher Concepts. J. Med. Eng. Technol. 2020, 45, 145-157. [CrossRef] [PubMed]

11. Bruzzone, L.; Quaglia, G. Review article: Locomotion systems for ground mobile robots in unstructured environments. Mech. Sci. 2012, 3, 49-62. [CrossRef]

12. Morin, P.; Samson, C. Motion Control of Wheeled Mobile Robots; Springer: Berlin, Germany, 2008.

13. Parmar, J.J.; Savant, C.V. Selection of Wheels in Robotics. Int. J. Sci. Eng. Res. 2014, 5, 339-343.

14. Martínez, J.L.; Mandow, A.; Morales, J.; Pedraza, S.; García-Cerezo, A. Approximating kinematics for tracked mobile robots. Int. J. Rob. Res. 2005, 24, 867-878. [CrossRef]

15. Zamanov, V.; Dimitrov, A. Tracked Locomotion and Manipulation Robots; Bulgarian Academy of Sciences: Sofia, Bulgaria, 2012.

16. Lokhande, N.G.; Emche, V.B. Mechanical Spider by Using Klann Mechanism. Int. J. Mech. Eng. Comput. Appl. 2013, 1, 13-16.

17. Brooks, R.A.; Flynn, A.M. Fast, cheap, and out of control. J. Br. Interplanet. Soc. 1989, 42, 478-485. [CrossRef]

18. Pavlak, A. Material Selection Analysis for the Development of an Integrated Surface Vehicle System; Southern Illinois University: Carbondale, IL, USA, 2016.

19. Ashby, M.F. Materials Selection in Mechanical Design, 3rd ed.; Jordan, H., Ed.; Butterworth Heinemann-Elsevier Science: Oxford, UK, 2005.

20. Güven, Y.; Coşgun, E.; Kocaoğlu, S.; Gezici, H.; Yilmazlar, E. Understanding the Concept of Microcontroller Based Systems to Choose the Best Hardware for Applications. Res. Inven. Int. J. Eng. Sci. 2017, 7, 38.

21. Rajan, C.; Megala, B.; Nandhini, A.; Priya, C.R. A Review: Comparative Analysis of Arduino Micro Controllers in Robotic Car. Int. J. Mech. Aerosp. Ind. Mechatron. Eng. 2015, 9, 371-380.

22. Pujari, S.; Panda, A.; Muduli, P.P.; Badhai, R.; Nayak, S.; Sahoo, Y. A Learning Model for 8051 Microcontroller Case Study on Closed Loop DC Motor Speed Control. Int. J. Emerg. Technol. Adv. Eng. 2013, 3, 2250-2459.

23. Willis, H.J. Automated Lawn Cutting and Vacuum System. U.S. Patent US7185478B1, 6 March 2007.

24. Martin, R.L. Automated Lawn Mower or Floor Polisher. U.S. Patent US4887415A, 19 December 1989.

25. Ruffner, B.J. Multifunctional Mobile Appliance. U.S. Patent US20020049522A1, 31 December 2002. 
26. Tanaji, S.V.; Chandrakant, C.S.; Shashikant, P.S.; Raju, G.O.; Bhalchandra, G.S. Automated mower robo. Int. Res. J. Eng. Technol. 2018, 5, 1-4.

27. Dewangan, A.K.; Raja, R.; Singh, R. Multi Sensor and Multifunctional Robot With Image Mosaic. Int. J. Sci. Eng. Technol. Res. 2014, 3, 677-680.

28. Wójcik, K. The Influence of the Cutting Attachment on Vibrations Emitted by Brush Cutters and Grass Trimmers. For. Res. Pap. 2015, 76, 331-340. [CrossRef]

29. Halley, M. Robomow RX12u Review. 2018. Available online: https:/ / easylawnmowing.co.uk/robomow-rx12u-review / (accessed on 19 November 2019).

30. Halley, M. Husqvarna 105 Automower Review. 2016. Available online: https://easylawnmowing.co.uk/husqvarna-105automower-review / (accessed on 19 November 2019).

31. Hales, D. iRobot Terra t7 Review. 2019. Available online: https://moderncastle.com/irobot-terra-t7-review/ (accessed on 19 November 2019).

32. Harivandi, A.; Gibeault, V.A. Mowing Your Lawn and Grasscycling, 1st ed.; Division of Agriculture and Natural Resources, Regents of the University of California: Oakland, CA, USA, 1999.

33. Feliciano, P.A.C.; Ong, K.A.G. Effectiveness of Musa Paradisiaca (Banana) Peel as an Alternative to Commercial Floor Wax for Household Use in the Philippines. Asia Pac. J. Multidiscip. Res. 2019, 7, 38-48. 